\title{
Governance in Times of the Big Data Revolution: Sri Lanka's Options
}

\author{
Harinda Vidanage ${ }^{1}$
}

SLJDA 2015 (5): 1-13

\begin{abstract}
This article looks at the management of the critical intersection of governance and technology. Both the concepts and frameworks that the two invoke are experiencing turbulence in navigating the recent global shifts. Governance, since its inception as a critical conceptual and policy framework encounters stiff academic and policy resistance in moving towards creating global governance architecture. Technology is a broad concept and in the context of utility it is extremely diverse. The article attempts to explore a recent phenomenon as a consequence of the information revolution; the rise of big-data and significant changes it has brought to social life. Big data is not just a corporate tool for extracting profits, but is a techno-resource making governance a complex task. Yet if it is well-handled it will increase the efficiency and accuracy of service delivery platforms in the public sector.

Comprehending the importance and deployment of data analysis emerging from big data would be a critical sphere that the public sector has to invest in and engage with. Even in the United States, Google seems to be outdoing every national data and statistical analysis and at the same time working with the federal government to deliver better services to the American citizens. Bigdata is a result of intense data creation by anyone connected to the Internet. The amount of data in the world is outgrowing not just the machines invented to process them but the human imagination. Thus it would be pragmatic for the Sri Lankan public sector to engage with big-data management through systems of governance.
\end{abstract}

Keywords: Sri Lanka, Governance, Big Data, Information Revolution, Global shifts

The post 1980s era witnessed the reinventing of public sector reforms globally, led by significant changes in Western societies which were influenced by the fall of the Soviet Union, and as many argued, the triumph of the neo-liberal agenda. In line with such global transformation, public sector reforms saw a new form of approach to governance; the idea of New Public Management (NPM) (Cochrane, 2000). Application of NPM resulted in scaling back of the role of government involvement in the public sector and the rise of associated agencies which were handed over many public sector services through service agreements. Thus, outsourcing the somewhat privatised public sector offerings became the hall mark of these reforms. These reforms facilitated the

1. The Author is Visiting Assistant Professor of International Relations and Cyber Politics at St. Lawrence University, Canton, New York. He holds a PhD in Politics from University of Edinburg, UK. The author can be reached on: hvidanag@stlawu.edu 
expanding of local and global connections in policy making which were at the heart of the governance debate which commenced in the late 80 's (Cochrane, 2000). Although the notion of NPM is contested and like many new constructs, is amorphous in nature, Politt's definition does help in understanding what it entails; according to him NPM is, 'a general theory or doctrine that the public sector can be improved by the importation of business concepts, techniques and values' (Politt, 2009, p. 201). As mentioned above, the notion of governance and its working can be understood in local, global and comparative perspectives. These seamless connections of governance between the local and the global were first identified in a book edited by Rossneau and Czempiel (1992). While the notion of NPM seems to be going out of favour amidst calls for good governance, the objective of this article is not to be prescriptive or provide a framework of solutions that is necessary in the context of the data revolution and service delivery in Sri Lanka, but will call for awareness, education, and policy application, mainly at levels of public administration and policy formulation on the implications of the data revolution and overall governance.

The complex debate on the 'data revolution' is at the core of this article whilst functioning as the key link connecting the notion and practice of contemporary governance. Governance itself is a concept, policy and process which has generated a significant amount of debate, disagreement and controversy over the last two decades since its inception, prompting Rod Rhodes (1997) to call it a vogue word for public sector reforms. Yet governance is seen as a form of pursuit for understanding the workings of daily life in society and looks at the flows of power, networks, and social organizations beyond the mere functions of government. This article will key in on how the data revolution is becoming a deep seated aspect of governance that affects society in general and generates social change, leading to significant debates about development, social arrangements, law, public order, business models, marketing and new forms of regulation.

This article starts with presenting the idea of governance and the close relationship of governance of the 21st century with information processes, technology and the data revolution. It then deals with the data revolution and looks at example scenarios and how the United States are responding to the massive social transformation that this revolution is bringing about. Then it presents mini cases of how governance and the data revolution have become integral aspects of State policy formulation and deals with the complications, challenges and even fears that the data revolution breeds surveillance struggles between State and non-State entities leading to the erosion of rights of citizens. An attempt to explain 
what all these transformations mean for the Sri Lankan administration services and what we can gain by re-imagining public service delivery and formulating mechanisms, research and policy as the 21st Century demands concludes this article.

Nearly two decades after the NPM experiment, even the ardent supporters of the systems saw it faltering, with failures and colossal losses for respective governments. The British public services sector which was a pioneer of NPM reforms saw scholars and policy makers calling for rethinking and a complete overhaul of the NPM system. Extreme disaggregation through NPM had created administrative complexities and failure to achieve levels of efficiency or innovation. Such drawbacks represented weaknesses in NPM models for anticipating and adapting to global transformation and translating administrative processes into better governance. NPM failed to grasp the technological revolution that revolutionised the ways and means of how people engaged with government, society and each other. These transformations came with the expansion of cyberspace and the transformation of the Internet into the Internet of everything (IOE), which denotes the expanding number of devices connected to the Internet and the increasing reliance of our lives and day to day activities on these connected devices (Michaels et al., 2010).

\section{Technology and Governance}

Ideas on governance emerged in the late 20th century when functions of governments started losing leverage with the increasing manoeuvrability of mobilised and organised elements in society breaking away from the monolithic control of governments in people's lives. Governance is part of the lexicon of social organization conceived to explain implications of a highly diverse nature of new social actors, political forces, identity groups and power networks that dominate both the local and social distribution of power and authority and how these entities contribute in creating regulations, procedures, policies, and practices and establish forms of governing (Weiss, 2013).

The important notion of governance is that it clearly signifies that States and internal State activities and the circuit of administration have systematic linkages with global processes. There is no more the monolithic insular State where the essential flows of power and authority are conceived merely within the State apparatus. Instead modern processes are clearly wired or wirelessly synchronized with global flows. Thus States find themselves constantly entangled with transnational and international settings. Governance is clearly a way of capturing and 
analysing and even making sense of how the States are responding to a changing world and an increasing number of stakeholders (Weiss, 2013).

The idea of Information technology (IT) solutions as part of a new mechanism of governance is seen in the ideas of the extremely influential scholar Patrick Dunleavy, who was a major force in the new labour movement which brought Tony Blair into power in the UK. He brought in an interesting notion of a new form of public administration which was classified as 'Digital Era Governance' (Dunleavy, 2010). The reason this article attempts to connect with Dunleavy is that within Dunleavy's framework there is a starting point to the discussion of big data which became a phenomenon in the second decade of the 21st century. Dunleavy's argument for established State control of public services and simultaneous utilization of information technologies through State led initiatives for the benefit of the citizenry, was a rebuttal of the NPM wave and acknowledgment of the sheer importance of the revolution when planning for future governance.

Dunleavy's conception of re-imagining the public service of the 21st century (2010) does reflect transformations of the public sector offerings in Sri Lanka, with the public sector trying to drive innovation and competition, creating a more flexible public service in the country. Such intent was clearly visible with the setup of the Information and Communications and Technology Agency (ICTA) of Sri Lanka for driving information solutions that target public sector reforms and spearheading digitisation of public services, ranging from making available public service documentation on electronic formats, establishing telephone hotlines to the creation of a government information service web repository in Sri Lanka.

While such mechanisms were looking at using the information revolution to be channelled through the apparatus of the State, there were vast transformations in the way the Internet based app industry and social media innovations which in the past four years have outpaced institutional adaptation even in the most advanced countries in the world. This rapid pace in the information environment seems to be challenging the idea of digital era governance, as States seem to be struggling to centralise information solutions as the private sector has created a massive industry out of the data that is created. The most revolutionary factor in this transformation is the fact that the information industries' largest data creators are the citizens themselves. 


\section{What is the data revolution?}

It has been nearly two decades since the Internet went commercial and it has been a decade since social media and digital architectures began to expand the Internet into what we call the Internet of things with more and more devices connected to the Internet, and to our lives from smart phones, smart homes, smart cars, health trackers, robot cleaners, to smoke alarms. All these devices are linked to the Internet which is harvesting data about our day to day lives ranging from our heart-rates, to the number of strides we take a day, to data on our preferences from food to politics. All these data are recorded and stored on the Internet. Secondly we do more work, collaboration, networking and storage of information online thus creating data in the form of emails, pictures we snap from our phones, tablet devices, digital cameras, to media content we consume and daily business transactions to online banking, thus leaving behind a massive digital trail of raw data leading to the creation of unprecedented amounts of data that could easily be used to build elaborate profiles of every user.

This data that we create, have become a source of a booming business and the source of a power struggle between companies and States, to win markets, gain information about citizens and concerns about who controls and what can be done with such data. Thus the data revolution has significant political implications at multiple levels.

The Obama administration came out recently with a report and policy document analysing its position on big data and the data revolution in the United States (2014). While pointing out elaborately the power of unexpected discoveries emerging from big data such as the advancement of human life, the report cautions and calls for a re-imaging of how the legal system, social ethics, social norms and the protection of privacy of individuals would work.

Emerging literature on the big data revolution reflects 'what' questions rather than 'why' questions. As Schonberger and Cukier (2013) argue, 'in a big data world by contrast, we won't have to be fixated on causality; instead we can discover patterns and correlations in the data that offer us novel and invaluable insights. The correlation may not tell us precisely why something is happening, but they alert us that it is happening' (2013, p. 14). Prior to delving into some mini cases where States have adopted ways and means of working with big data and collaborating with non-State actors to find better results for increasing public services, it is important to grasp the math that leads to this so called data revolution. Cisco (2011), predicts that by 2020 there will be at a minimum 
17 billion devices connected to the Internet and there is a possibility of these numbers near tripling. With nearly half of the world population connected online, even in 2012 Facebook was claiming that it was processing 2.5 billion pieces of content. The McKinsey Group's report that came out recently titled 'Digital flows of 2013' (Manyika et al, 2014) points out that eight hundred million Skype international call minutes have been utilized in 2012, and if that is put into context compared to a decade ago half of humanity never made a phone call.

In the context of Sri Lanka, it is easy to dismiss the impact of the data revolution by claiming that there is still no critical mass of Internet users, but the point is to develop public services using such technologies for enhancing the overall service offerings. Examples from the United States and Pakistan are presented as mini cases. Apart from their cold war cooperation and on and off linkages due to geo political pressures, these two systems of governance are vastly different and incompatible, yet they both have found significant use of big data to deal with similar challenges internally. Since the appearance of viruses that caused the swine and bird flu outbreaks globally which were known as H1N1, the United States apex center for coping with such challenges, the 'Center for Disease Control and Prevention' better known as CDC made a federal request to doctors to inform them of new flu cases, because even with the CDC total commitment and connections, the data they were receiving about the flu were outdated by at least two weeks. When, fighting an epidemic that has the proportion of spreading fast and creating a pandemic, a two week delay of gathering data was a significant setback. Yet in 2009 when these epidemics stuck, CDC was bolstered by an un-anticipated ally, the software giant Google. Unknowingly to CDC, Google had been tracking winter flu outbreak patterns simply by analysing data on what people searched for in relation to flu (Schonberger and Cukier, p. 1, 2013). For example Google tracked common search terms such as the availability of flu vaccines, flu medication, advice on precautions etc., and nearly 50 million common search terms linked to the flu were analysed thus. Google had real time data of where the flu was hitting hard within the United States and they even had an understanding of global flu outbreaks and was able to do a projection of flu trends globally (Schonberger and Cukier, p. 1, 2013). Google flu analysis is still online. Thus in 2009 when H1N1 outbreak struck the United States, CDC coped with containing it successfully thanks to the real time data generated by Google. Google is significantly expanding its interventions and interactions with States, civil society and the private sector, concentrating on various levels and models of service delivery. The interesting takeaway is that the transforming and transcending of boundaries between State and non- 
State service providers leads to collaborations and alliances that can be built to provide better service to citizens.

In case the experiences from the United States and entities like Google are to be denounced on the grounds of incompatibility, the Pakistani experience would be an eye opener. It is not just the relevance of an experience from a South Asian nation, but the real parallel lies with the issue at stake. The Pakistani situation was an outbreak of dengue fever which was going beyond the control of health authorities in the province of Punjab in 2012. A key challenge to the Pakistani health authorities was the lack of data on fatalities, break outs and breeding grounds of mosquitoes for co-ordination among health facilities. With 20,000 plus cases and rising fatalities the Punjabi state turned to its key IT agency, the Punjabi Information Technology Board (PITB) for help.

PITB which was set up by the State government to harness the power of information technology to improve the business sector and government service delivery came out with a novel idea to combat dengue (Sathe, 2014).

Whilst Sri Lanka suffers from similar problems of dengue outbreaks, our coping mechanisms are focused on seeking containment strategies or global support to combat the spread of the carriers. The Punjab State Administration sought to gain a total picture of the outbreak, primarily by seeking the data for locating the breeding grounds and areas most affected. This strategy provided the Punjabi officials with a clear map of the outbreak, thus opening the field to a targeted dengue eradication campaign (Sathe, 2014). All these were achieved by the integration of a unique homemade App and providing cheap smart phone devices to all the staff engaged in the anti-dengue campaign, from health practitioners to the individuals who carried the chemical spray guns. They were specifically instructed to take photos of everything they did; from sites they sprayed, to patient's houses, and geo tag these pictures. Thus, after a while the health authorities started getting an elaborate sense of the outbreak and could divert attention to critical areas and at the same time update their campaign on real time using the specially designed App.

The data driven counter attack enabled the Punjabi State authorities to manage and contain the outbreak and dengue is no longer on an epidemic level in the State. This experiment has prompted the Pakistani government to expand such innovative aspects of Apps, smart phones are delivered for other government services and the success of the dengue containment project has attracted World Bank funding. Developing applications and spending on smart devices are not extravagant costs 
for governance. Properly coordinated with human resources, such data collection and data utilization can provide significant relief for major issues in Sri Lanka from predicting an outbreak of an epidemic to understanding how to respond to droughts, coordinating drought relief, enhancing food security and creating a more secure and healthy society.

These two mini case examples are important for comprehending both the power of big data as well as the ability to make real world transformations to solve problems that are holding back progress in any society. The United Nations initiated its own program on using big data as part of its development strategy and is currently focusing on a multitude of African countries in carrying out this program, titled the Global Pulse (United Nations Global Pulse) initiative. The UN initiative very clearly claims, 'Global Pulse is a flagship innovation initiative of the United Nations Secretary-General on big data. Its vision is a future in which big data is harnessed safely and responsibly as a public good' (UN). The United Nations Global pulse project is looking at the opening up of government data, increasing the efficiency of data collection and encouraging the private sector to share its data so that better development policies could be formulated. Thus, examples vary from such global scale initiatives to global city initiatives. Singapore has launched a ten year plan to develop overall data analytic capabilities of the government to improve the global standing of the Singaporean governance system.

\section{Challenges and fears}

Despite the narratives of the importance of big data and the overall data revolution, governments, transnational bodies and International organizations are concerned about data mismanagement. Big data is classified as the new oil that drives the 21st Century. Nearly $90 \%$ of the world's total data was generated in the past two years (Barton 2014), leading to the emergence of a new set of elites who control and own data in society who have the ability to significantly influence local and global politics.

The debate is quite complex and it involves many stakeholders, with rights groups calling for States and corporates to limit surveillance into private lives. Security establishments in governments are overwhelmed with the amount of data being created and are urging governments to spend millions of dollars to create data capturing and analysis infrastructure for the sake of national security. Corporate interests and national interests are clashing over the control of data while international implications are even more complicated, from hackers attacking major data storage sites, from stealing credit card information, to more serious 
crimes of industrial espionage emanating from State led covert efforts. Recently there has been a surge in trading of allegations by both USA and China on cyber spying and industrial espionage (Macleod, 2014).

In this context what we witness is a situation of a struggle not just for data ownership or control but a complex field of struggle for cyber power. Cyber Power is a controversial concept populated with a multitude of definitions and disagreements. According to Joseph Nye, cyber power represents 'the ability to obtain preferred outcomes through the use of the electronically interconnected information resources of the cyber domain' (Nye, 2012, p.123). This behavioural definition captures the current struggle for controlling the data flow. The alarming factor is that there is an accelerated effort by States for information control in societies. A classic example of such efforts came to light in recent revelations of the American National Security Agency (NSA) driven mass surveillance program called PRISM. American whistleblower Edward Snowden and Guardian newspaper journalist Glen Greenwald released elaborate details of the program and the astonishing levels of surveillance. The PRISM program is basically an advanced software solution that is capable of mass surveillance of the communication networks which include cellular and the Internet. Increased surveillance is not merely limited to the Western world; it is in every part of the globe where States are trying to use national security as a pretext for increased surveillance of private lives. Information corporates such as Google, Facebook, Tencent and Baidu, all collect millions of consumer data. Former Whitehouse cyber Czar Richard Clarke points out that by 2040 private information or data about where we are, with whom we are and what we might be doing at any given moment will be known to governments and corporates alike with the use of advanced surveillance and data gathering technology (Clark, 2014).

The serious concern arising from the above factoris that in the near future privacy and advocacy groups probably will run out of steam or be overwhelmed by corporate interests and succumb to increasing securitisation of digital content by governments. Thus, individual rights of privacy may be a nonexistent factor in the near future, as the data revolution may become part of data warfare. This is a real and serious issue which any State and its administration system need to take into consideration.

In this back drop a new idea of data regulation has emerged, mainly from data and information scientists, conceptually identified as 'algorithmic regulation'. This concept urges governments to play a more active role in vetting the data environment by adopting the development of superior 
algorithms that can control most cyber content and processes that are driven by algorithms. The argument behind Algorithmic regulation mooted by O' Reilly, who is famous for coining the term web 2.0 (2013), is that most information innovations on cyber platforms emerge from new algorithms. For example, all of Google and its allied services from Google trends to Google docs are run on smart algorithms. Thus the argument is that if you need to be in control, ensure that these new innovations such as financial instruments from Bitcoin, Square to electronic cash processes can be managed by more advanced algorithms and programs. He argues that Google has its own regulation systems that manage its algorithms and thus governments also have to take into account such regulations. But cyber critics such as Evgeny Morozov (2014) strongly disagree with such implementations saying it will bring in the death of politics and people's individual rights. With the increase of such mechanized forms of regulation, one major compromise will be the diminishing functions of day to day politics and political interaction. More machinic governance such as algorithmic regulation maybe better for companies and if States adopt such measures the whole equation of political duties and responsibilities will dissipate, leading to significant alienation of society (Morozov, 2014)

\section{What is good for improving governance in Sri Lanka}

Reverting to the intention of this article, what one can see is the enthusiasm and the emerging concerns among academics and activists on the implications of the data revolution and what happens at the intersection of the data revolution and governance. Thus given this persistent tension between the State, corporates and civil society over the control and influence of data, the Sri Lanka public sector successfully engaged its citizenry, and diversified its services with the collaboration of the ICT Agency, from local governance mechanisms to a digitised Immigration Department, Department of Motor Traffic etc, which could provide the necessary backbone to create an integrated data sharing division or team of data analysts to enhance the Sri Lankan public sector service delivery.

It will provide governance structures and agents a great opportunity to work locally and globally, converging and pooling in resources from various sectors. The final section of this article focuses on the programs and successes of ongoing collaborations globally where governance spaces have opened up to global collaboration for the betterment of service delivery and generating a significant knowledge bank. The key factor here is human resources. There is a tendency to give information technology professionals all responsibilities related to information 
technologies; this is a recurring fallacy in many countries. The data revolution has demanded a course correction and a requirement for totally new areas of expertise. The requirements stem from the need to recruit data scientists and educate future data scientists to develop skills in data analytics.

The best example for the above aspect comes from China, with much being discussed, researched and written about contemporary China ranging from geo politics, economy to Asian century, pointing to China as the vanguard nation of the 21st Century. Another reason China is achieving so much success is its vision for the future and its greater willingness to collaborate with global stakeholders. Late last year under a program codenamed IBM U 100, IBM Corporation of the United States donated big data analysis software worth one hundred million dollars to one hundred selected Chinese universities. While on the normative front it was a great business deal for IBM, which anyway makes nearly two thirds of its profits from overseas operations, in the long run it will help Chinese universities churn out the much needed data analytic experts for the future. China itself is projected to achieve a seven fold increase in the big data and market services internally, from 77.6 million in 2011 to 617 million US Dollars by 2016 (Larsen 2013). One of China's biggest e-tailers Alibaba.com restructured its operations structure in early 2014, which created 800 new jobs for data analysts. Larsen in his article quotes Meng Su a leading Chinese academic in China's premier business school Guanghua School of Management, University of Beijing who claims, 'China will soon become the world's largest data market', and thus job seekers in the future should think of choosing career paths to become 'data scientists' (Larsen 2014). The German team which won the football 2014 were significantly successful due to a massive investment on a big data analytics that provided the players and the management day to day evaluation of all their opponents and provided them with an advanced game strategy which was very evident in the final game which they played with Argentina (Norton: 2014). The German example of a football team partnering with the enterprise resource planning giant SAP to gain an advantage is a very important example of the massive potential of big data that can be deployed in numerous fields for advancement of national goals.

\section{Conclusion}

When it comes to technology, innovation and information technologies for good governance, counter arguments have been ripe but it is encouraging to see Sri Lanka embracing the need for technological 
advancement. Even within the United States there is no total IT literacy, nearly $50 \%$ of Americans perceive cloud computing has something to do with the weather and many do not realise that basic interactions such as online banking, storing documents on Google docs or drop box or purchasing goods or services from Amazon.com or Netflix.com are part of cloud computing (Brown et al 2011). Thus there is always the barrier of knowledge, intent and adapting to technology fused social transformations but when countries such as Uganda, Bolivia, Ecuador are creating technological eco systems to improve governance, the debate on implementing data driven service components in the Sri Lankan public sector either signifies lack of institutional autonomy or the influence of political forces and special interest groups acting as spoilers. Though challenges in the nature of political interferences are common both in the developed and the developing world, creating mechanisms to reap the benefits of the data revolution can make a win-win situation for the public sector, political leadership and the citizenry, thus creating an iron triangle of relationships between the three stakeholders that would provide much needed progress and development in Sri Lankan society. The task at hand may have no historical precedent or contemporary parallel, but will surely define future relativity of the institutions of public administration and its value in Sri Lanka.

\section{References}

Barton, Dominic. (2014) Age of Disruption

Retrieved from http://www.project-syndicate.org/commentary/dominic-bartonexplains-why-the-global-impact-of-the-data-revolution-will-surpass-that-of-theindustrial-revolution

Brown, Brad., Chui, Michael., Manyika. (2011). Are you ready for the era of 'big data'? Retrieved from http: http://www.mckinsey.com/insights/strategy/are_you_ready_ for_the_era_of_big_data

Chui, Michaels., Loffler, Markus., Roberts Roger. (2010).

The Internet of Things

Retrieved from http://www.mckinsey.com/insights/high_tech_telecoms_Internet/ the_Internet_of_things

Clarke, Richard (2014). Richard Clarke on the Future of Privacy: Only the Rich Will Have It Retrieved from http://online.wsj.com/articles/richard-clarke-on-the-future-ofprivacy-only-the-rich-will-have-it-1404762349

Cochrane, Allen. (2000). Local government: Managerialism and modernisation. In John Clark, Sharon Gewirtz, and Eugene McLaughlin, New managerialism, new welfare? London: Sage.

Dunleavy, Patrick, and Helen Margetts. (2010). The second wave of digital era governance. Paper presented at the American Political Science Association Conference, Washington, DC,September 4 (unpublished).

Retrieved from http://eprints.lse.ac.uk/27684/1/The_second_wave_of_digital_era_ governance_\%28LSERO\%29.pdf 
Evans, Dave. (2011). The Internet of Things How the Next Evolution of the Internet Is Changing Everything

Retrieved from http://www.cisco.com/web/about/ac79/docs/innov/IoT_ IBSG_0411FINAL.pdf

Larson, Christina. (2013) In China, Big Data Is Becoming Big Business

Retrieved from http://www.businessweek.com/articles/2013-05-29/in-china-bigdata-is-becoming-big-business

Manyika, James., Bughin Jacques., Lund, Susan., Nottebohm, Olivia., Poulter, David., Jauch, Sebastian., Ramswamy, Sree. (2014) Global flows in a digital age Retrieved from http://www.mckinsey.com/insights/globalization/global_flows_ in_a_digital_age

Macleod, Calum. (2014) China accuses U.S. of hacking. Retrieved from: http://www.usatoday.com/story/news/world/2014/05/19/chinahacking/9293521/

Morozov, Evgeny. (2014). The rise of data and the death of politics Retrieved from http://www.theguardian.com/technology/2014/jul/20/rise-of-datadeath-of-politics-evgeny-morozov-algorithmic-regulation

Mayer, Viktor., Cukier Schonberger Kenneth. (2013) Big Data: A Revolution that will transform how we live, work and Think. Boston, New York: Eamon Dolan.

Norton. Steven. (2014). Germany's 12th Man at the World Cup: Big Data Retrieved From http://mobile.blogs.wsj.com/cio/2014/07/10/germanys-12th-manat-the-world-cup-big-data/

Nye Jr, Joseph.( 2011). The Future of Power. New York, NY: Public Affairs. 113 p 122

O'Reilly, Tim. (2013) Open Data and Algorithmic Regulation in Goldstein, Brett and Dyson Lauren, Beyond transparency (pp 289 - 301). Code for American press: San Francisco, CA

Retrieved fromhttp://beyondtransparency.org/chapters/part-5/open-data-andalgorithmic-regulation/

Pollitt, Christopher. (2009). Bureaucracies remember, post-bureaucratic organizations forget? Public Administration 87,198-218.

Rhodes, R.A.W. (1997). Understanding governance: policy networks, governance, reflexivity and accountability. Maidenhead, GB,Philadelphia, US: Open University Press.

Rosenau, James N., Czempiel, Ernst-Otto. (1992).Governance without Government: Order and Change in World Politics (ambridge Studies in International Relations). Cambridge: Cambridge University Press.

Sathe, Gopal. (2014). What India Can Learn About E-Governance From Pakistan Retrieved from http://gadgets.ndtv.com/mobiles/features/what-india-can-learnabout-e-governance-from-pakistan- 574650

Weiss, Thomas. (2013) Global Governance:Why? What? Whither? Cambridge: Polity Press.

Big Data: Seizing Opportunities, Preserving Values (2014). Executive Office of the President.

Retrieved from http://www.whitehouse.gov/sites/default/files/docs/big_data_ privacy_report_5.1.14_final_print.pdf 